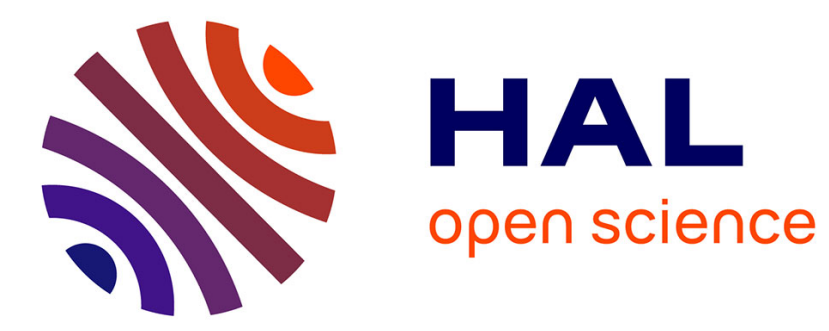

\title{
DIPOLE-EXCHANGE SPIN WAVE SOLITONS IN YIG FILMS
}

B. Kalinikos, N. Kovshikov, A. Slavin

\section{To cite this version:}

B. Kalinikos, N. Kovshikov, A. Slavin. DIPOLE-EXCHANGE SPIN WAVE SOLITONS

IN YIG FILMS. Journal de Physique Colloques, 1988, 49 (C8), pp.C8-1583-C8-1584. 10.1051/jphyscol:19888724 . jpa-00228963

\section{HAL Id: jpa-00228963 https://hal.science/jpa-00228963}

Submitted on 1 Jan 1988

HAL is a multi-disciplinary open access archive for the deposit and dissemination of scientific research documents, whether they are published or not. The documents may come from teaching and research institutions in France or abroad, or from public or private research centers.
L'archive ouverte pluridisciplinaire HAL, est destinée au dépôt et à la diffusion de documents scientifiques de niveau recherche, publiés ou non, émanant des établissements d'enseignement et de recherche français ou étrangers, des laboratoires publics ou privés. 


\title{
DIPOLE-EXCHANGE SPIN WAVE SOLITONS IN YIG FILMS
}

\author{
B. A. Kalinikos $\left({ }^{1}\right)$, N. G. Kovshikov $\left({ }^{1}\right)$ and A. N. Slavin $\left({ }^{2}\right)$ \\ (1) V. I. Ulyanov (Lenin) Electrical Engineering Institute, 197022, Leningrad, U.S.S.R. \\ $\left({ }^{2}\right)$ Leningrad Shipbuilding Institute, 190008, Leningrad, U.S.S.R.
}

\begin{abstract}
The experiments demonstrating nonlinear dynamics of propagating dipole-exchange spin waves (SW) in YIG films are described. It is shown that SW input pulse with the increase of its duration and amplitude splits into envelope solitons, demonstrates modulational instability and formation of strange attractor according to the Ruelle-Takens scenario.
\end{abstract}

In our papers [1-3] we reported observation of two nonlinear effects in yttrium-iron garnet (YIG) films: formation of spin-wave (SW) envelope solitons and modulational instability of finite amplitude travelling SW. The observation of these nonlinear effects was based on the peculiarities of dipole-exchange SW spectrum in thin YIG film [4].

The aim of this paper is to report our recent progress in the experimental study of the nonlinear SW dynamics in monocrystal YIG films.

\section{Experiments}

The experimental arrangement for excitation and reception of SW was like a usual delay-line consisting of two strip-line transducers (width $-3 \times 10^{-2} \mathrm{~mm}$, length $-4 \mathrm{~mm}$, distance between transducers $-3-10 \mathrm{~mm}$ ). In our experiments we used perpendicularly magnetized YIG films (thickness $L=(3-8) \times 10^{-4} \mathrm{~cm}$, $\Delta H=0.2-0.3$ Oe, orientation (111)) with pinned surface spins. Dipole-dipole interaction between spin waves of equal symmetry in such films leads to the considerable repulsion of the dispersion branches and, as a result, to the formation of "gaps" in the dipoleexchange SW spectrum $[1,4]$.

To obtain soliton regime of SW propagation in YIG film $\left(L=5.8 \times 10^{-4} \mathrm{~cm}, \Delta H=0.2 \mathrm{Oe}\right)$ we used pulsed excitation [3]. The upper tracks of the oscillograms figure 1 mark the time positions of the input pulse of the duration $T=180$ ns. The lower tracks show the envelopes of the SW pulses transmitted through the YIG film. Oscillograms figures A, B, C were taken when the carrier frequency $\omega$ varied from $\omega_{1}$ to $\omega_{2}$ near the "gap" centered at the frequency $4439 \mathrm{MHz}$ (see fragment J). It can be seen that at $\omega=\omega_{1}$, situated between two neighbouring "gap" where dispersion is relatively low, the usual delayed pulse is obtained (A). When carrier frequency is shifted into the region of high dispersion $\left(\omega=\omega_{2}\right)$ the SW pulse spreads and its amplitude decreases (B, C). Oscillograms (C-F) were obtained at the fixed frequency $\omega=\omega_{2}$ when the power $P_{\text {in }}$ of the input pulse increased gradually. It can be seen that at a certain level of $P_{\text {in }}$ spin system nonlinearity com-

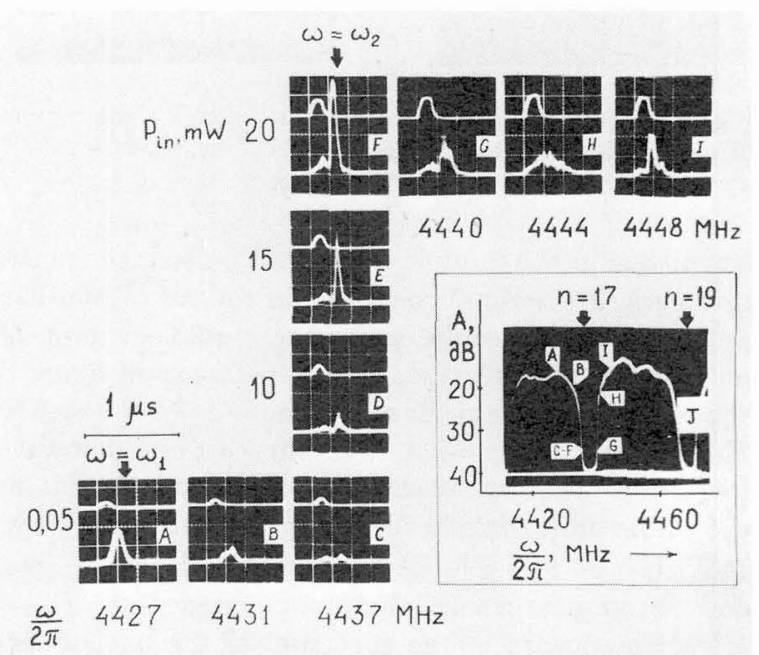

Fig. 1. - (A-I) Formation of the envelope soliton from the input pulsed signal ( $T=180 \mathrm{~ns}$ ); $(\mathrm{J})$ - dipole "gap". in the dipole-exchange SW spectrum of the YIG film.

pensates dispersion, so that the high and narrow peak $\left(T_{\mathrm{s}}=120 \mathrm{~ns}\right)$ appears in the place of the delayed pulse, i.e. spin wave envelope soliton is formed $(\mathrm{E}, \mathrm{F})$. We name this peak a SW envelope soliton in accordance with physical definition of soliton being a result of a balance between selfsteepening effects of nonlinearities and spreading effects of dispersion [5]. It is worth noting, that in all our experiments formation of envelope solitons took place only in the spectral regions of high dispersion where the Lighthill criterion is satisfied and the influence of dispersion (and nonlinearity)) on the input pulse profile is great compared to the influence of SW dissipation (point C-F in Fig. 1J) $[1,3]$.

Besides the above described soliton phenomena we have previously reported the effect of modulational instability of dipole-exchange SW in YIG films [2]. Here we report the observation of transition from the soliton regime to the regime of modulational instability taking place when the duraction $T$ of the input pulse is increased. 
To study this transition stage $T$ was chosen equal to $8 \times 10^{3}$ ns which is much longer than the period $T_{m}$ of the modulational instability $\left(T_{\mathrm{m}}=150-200 \mathrm{~ns}\right.$ [2]). Figure 2 shows the oscillograms and spectrograms of pulsed signal transmitted through the YIG film with the carrier frequency corresponding to the point $\mathrm{C}-\mathrm{F}$ in figure $1 \mathrm{~J}$. It is clear that two different parts can be dis-
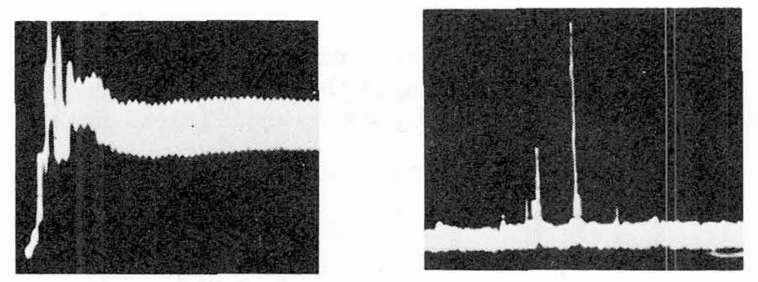

Fig. 2. - Transition from the soliton regime to the regime of modulational instability $\left(T=8 \times 10^{3} \mathrm{~ns}, P_{\mathrm{in}}=12 \mathrm{~mW}\right)$.

tinguished in the form of the output pulse: the transition part $\left(T_{\mathrm{t}} \sim 900 \mathrm{~ns}\right)$ consisting of several soliton-like pulses, and the regular part where stable regime of modulation is established. The spectrogram figure 3 shows one satellite peak of the modulation frequency $F_{\mathrm{m} 1}=5 \mathrm{MHz}$ lying lower than the carrier microwave frequency. This modulation frequency corresponds to the stable limit cycle in the phase space of the system.

With the increase of the input power $P_{\text {in }}$ second incommeasurable modulation frequency $F_{\mathrm{m} 2}=$ 1.1 $\mathrm{MHz}$ appears in the spectrum of the output signal (Fig. 3A). This can be interpreted as formation of a two-dimensional torus in the phase space of the system. With the further increase of $P_{\text {in }}$ the modulation spectrum becomes more complicated (Fig. 3B), and at last a broad peak of chaotic modulation is formed (Fig. 3C). The appearence of chaotic modulation in the spectrum of the systems corresponds to the formation of a stochastic (or strange) attractor in the phase space. The observed route to chaos seems to follows the Ruelle-Takens scenario [6].

The above described soliton effects have been theoretically interpreted in terms of nonlinear Schrödinger equation (NSE) with small dissipative perturbation [3]. Numerical calculations show that the perturbed NSE can be used for qualitative explanation of the observed SW chaotic dynamics (Fig. 3). It seems probable that the results of the recent nonlinear experiments [7] can also be interpreted in the frames of the same theoretical approach.

\section{Conclusion}

This work experimentally proves that epitaxial YIG film is a unique media for observation and investigation of nonlinear spin wave dynamics.
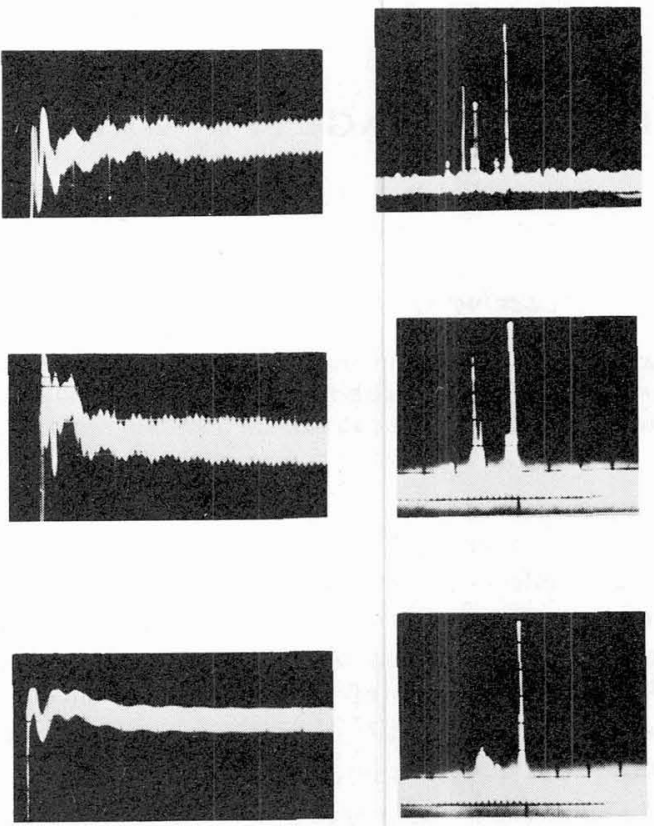

Fig. 3. - Development of the modulational instability $(\mathrm{A}, \mathrm{B})$ and formation of the strange attractor (C) $(T=$ $8 \times 10^{3} \mathrm{~ns}, P_{\text {in }}=16 \mathrm{~mW}(\mathrm{~A}), P_{\text {in }}=20 \mathrm{~mW}(\mathrm{~B}), P_{\text {in }}=26 \mathrm{~mW}$ (C)).

In one sample of the YIG film with pinned surface spins at a room temperature one can observe formation of envelope solitons of highly dispersive spin waves (Fig. 1), modulational instability of these waves (Fig. 2), and formation of strange attractor through the destruction of two-frequency quasiperiodic motion (Fig. 3).

\section{REFERENCES}

[1] Kalinikos, B. A., Kovshikov, N. G., Slavin, A. N., JETP Lett. Moscow 38 (1983) 413.

[2] Kalinikos, B. A., Kovshikov, N. G., Slavin, A. N., Sov. Tech. Phys. Lett. Leningrad 10 (1984) 392.

[3] Kalinikos, B. A., Kovshikov, N. G., Slavin, A. N., Zh. Eksp. Teor. Fiz. (JETP) Moscow 94 (1988) N2 159.

[4] Kalinikos, B. A., Slavin, A. N., J. Phys. C Bristol 19 (1986) 7013.

[5] Solitons, Eds. R. K. Bullough, P. J. Caudrey (Springer-Verlag, Berlin-Heidelberg-New York) 1980.

[6] Ruelle, D., Takens, F., Commun. Math. Phys. 20 (1971) 167.

[7] DeGasperis, P., Marcelli, R., Miccoli, G., Phys. Rev. Lett. 59 (1987) 481. 